\title{
CARACTERIZAÇÃO DA REDE DE DRENAGEM E CORRELAÇÃO COM A DEFORMAÇÃO NEOTECTÔNICA (BACIA DO RIO JUARA- ES, SUDESTE DO BRASIL)
}

\author{
Gabriel Pedro Alves Lopes ${ }^{(a)}$, Luiza Leonardi Bricalli ${ }^{(b)}$ \\ (a) Centro de Ciências Humanas e Naturais/ Universidade Federal do Espírito Santo, gabriel14pedro@gmail.com \\ (b) Centro de Ciências Humanas e Naturais/ Universidade Federal do Espírito Santo, luiza.bricalli@ufes.br
}

\section{EIXO: SISTEMAS GEOMORFOLÓGICOS: ESTRUTURA, DINÂMICA E PROCESSOS}

\begin{abstract}
Resumo
Esta pesquisa teve como objetivo caracterizar a rede de drenagem sob o aspecto da neotectônica, a fim de investigar o controle dos mecanismos neotectônicos na organização da rede de drenagem da bacia do rio Juara (Espírito Santo-sudeste do Brasil). Nesta área, destacam-se aspectos peculiares da drenagem: canais fluviais geometricamente organizados, corpos lacustres alinhados, com limites retilíneos, bacia assimétrica, além de feições morfotectônicas, tais como alvéolos de sedimentação, estrangulamento de vale e facetas triangulares. Os procedimentos para atingir o objetivo foram elaboração de mapa de padrões de drenagem com controle tectônico ou morfoestrutural e cálculo de assimetria de bacia, através de técnicas de geoprocessamento e geoestatísticas, na escala 1:50.000. Os resultados obtidos indicam que a bacia do rio Juara se apresenta assimétrica em todos os 7 (sete) transectos, com basculamento de bloco para NE e que os padrões de drenagem, em sua maioria, apresentam forte controle tectônico.
\end{abstract}

Palavras chave: assimetria de drenagem. padrões de drenagem. neotectônica. bacia do rio Juara.

\section{Introdução}

Há uma notória relação entre Neotectônica e aspectos da morfologia das paisagens atuais, sendo a rede de drenagem indicador particularmente sensível de movimentações neotectônicas. Pelo fato da drenagem refletir mesmo os movimentos de pequena amplitude, diversos autores indicam os estudos da rede de drenagem como etapa importante para a investigação tectônica (HOWARD, 1967; SCHUMM, 1986; SUMMERFIELD, 1987; BISHOP, 1995; COX, 1994; HOLBROOK \& SCHUMM, 1999; BRICALLI e MELLO, 2009; BRICALLI, 2011; BUSATO, 2014).

A área de investigação proposta neste estudo refere-se à bacia hidrográfica do rio Juara (Figura 1), localizada no estado do Espírito Santo, local onde ocorrem elementos fisiográficos que evidenciam prováveis controles neotectônicos: rede de drenagem onde os canais fluviais apresentam-se geometricamente organizados, presença de corpos lacustres alinhados, com limites retilíneos, bacia assimétrica, além de feições morfotectônicas, tais como alvéolos de sedimentação, estrangulamento de vale, facetas triangulares (SOUZA, 2015). 


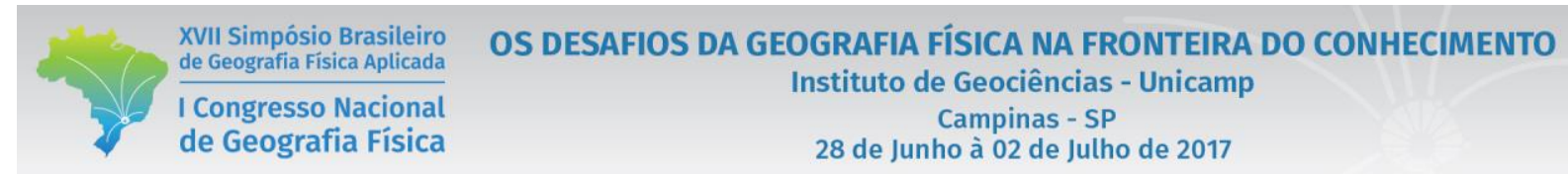

A presente pesquisa teve como objetivo principal caracterizar a rede de drenagem sob o aspecto da neotectônica, a fim de investigar o controle dos mecanismos neotectônicos na organização da rede de drenagem da bacia do rio Juara (Espírito Santo-sudeste do Brasil).

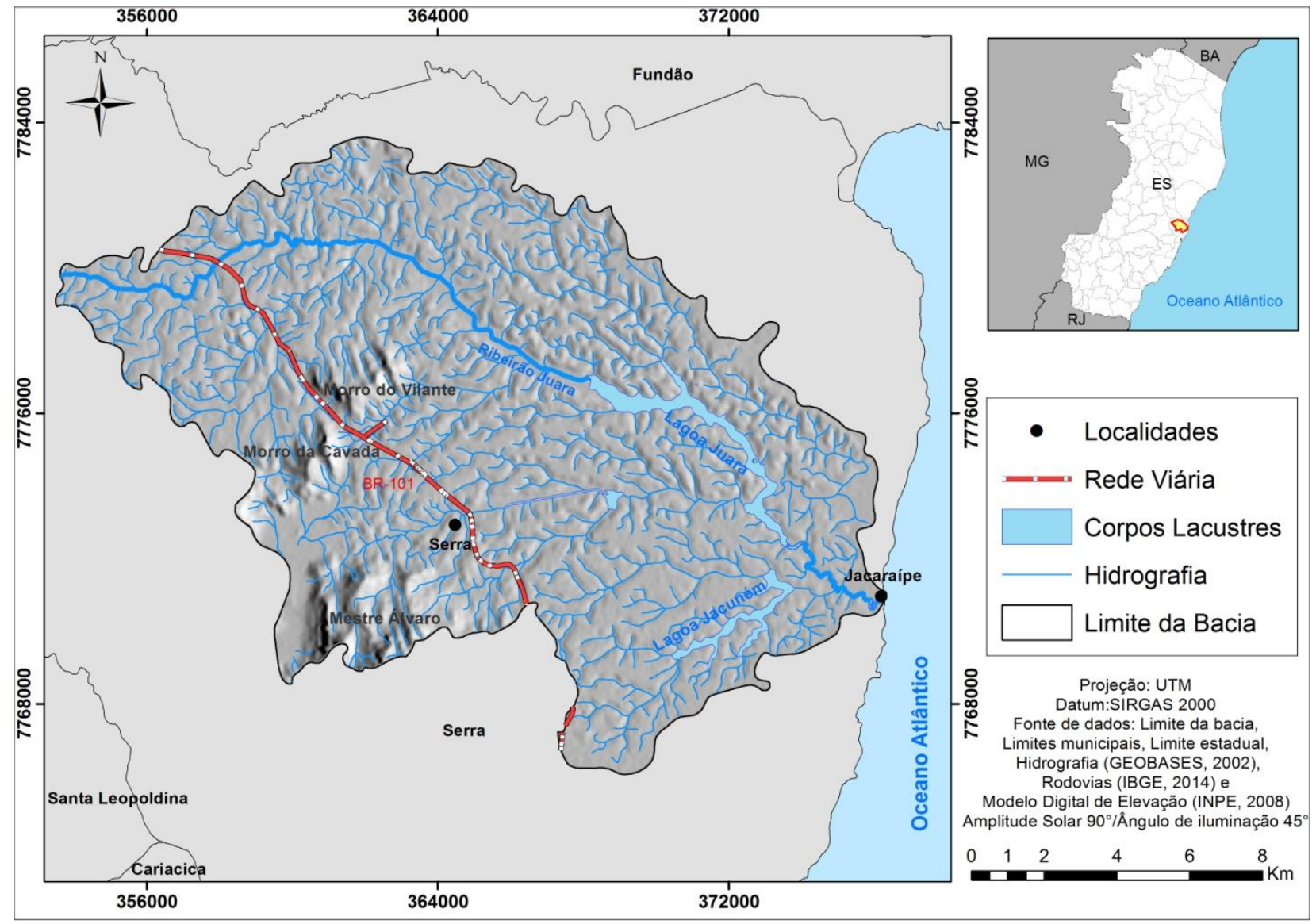

Figura 1 - Mapa de localização da bacia do rio Juara (município de Serra, estado do Espírito Santo, sudeste do Brasil)

\section{Materiais e Métodos}

2.1 Cálculo de assimetria de bacia hidrográfica

A análise da assimetria da bacia foi realizada sobre a rede de drenagem da base digital do Geobases (2002), escala de 1:50.000, com uso do software ArcGIS 10.1 $1^{\mathrm{TM}}$ (ESRI, 2012). Utilizou-se a fórmula $\mathrm{T}=$ $\mathrm{Da} / \mathrm{Dd}$, que representa a razão da distância entre o meio da bacia e o canal (Da) e a distância do meio da bacia e divisor da mesma (Dd). Quanto mais próximo de 1 for esta razão (Fator de Simetria Topográfica 


\section{OS DESAFIOS DA GEOGRAFIA FÍSICA NA FRONTEIRA DO CONHECIMENTO \\ Instituto de Geociências - Unicamp \\ Campinas - SP \\ 28 de Junho à 02 de Julho de 2017}

Transversa), maior é a assimetria de uma bacia e maior é a influência tectônica. Segundo Cox (1994), essa metodologia associa as assimetrias identificadas a basculamentos de blocos tectônicos.

2.2 Análise dos Padrões de drenagem com controle tectônico ou morfoestrutural

Foi realizada sobre a rede hidrográfica da bacia do rio Juara da base digital do Geobases (2002), escala de 1:50.000, com uso do software ArcGIS 10.1 TM (ESRI, 2012). Para identificação e classificação dos padrões de drenagem com controle tectônico e morfoestrutural foram utilizados os padrões de drenagem considerados por Howard (1967), Lima (2002) e Bezerra (2003).

\section{Resultados e Discussões}

Os resultados obtidos indicam que a bacia do rio Juara se apresenta assimétrica em todos os 7 (sete) transectos, estando todos muito próximos de 1, com indicação de basculamento de bloco para NE. Os transectos 2, 3 (oeste da bacia) e 7 (lesta da bacia) são os mais assimétricos (Tabela 1 e Figura 2). Esses cálculos indicam um possível controle tectônico na bacia e as assimetrias identificadas são relacionadas à basculamentos de blocos tectônicos (COX, 1994).

Tabela 1 - Valores de Cálculo para o Fator de Simetria Topográfica Transversa da bacia do rio Juara.

\begin{tabular}{cccc}
\hline Transectos & Da & Dd & T \\
\hline $\mathbf{1}$ & 1,086 & 1,637 & 0,663 \\
$\mathbf{2}$ & 4,952 & 7,022 & 0,705 \\
$\mathbf{3}$ & 4,626 & 6,831 & 0,677 \\
$\mathbf{4}$ & 2,839 & 4,628 & 0,613 \\
$\mathbf{5}$ & 2,695 & 4,668 & 0,577 \\
$\mathbf{6}$ & 3,784 & 5,915 & 0,639 \\
$\mathbf{7}$ & 1,894 & 2,688 & 0,704 \\
\hline
\end{tabular}




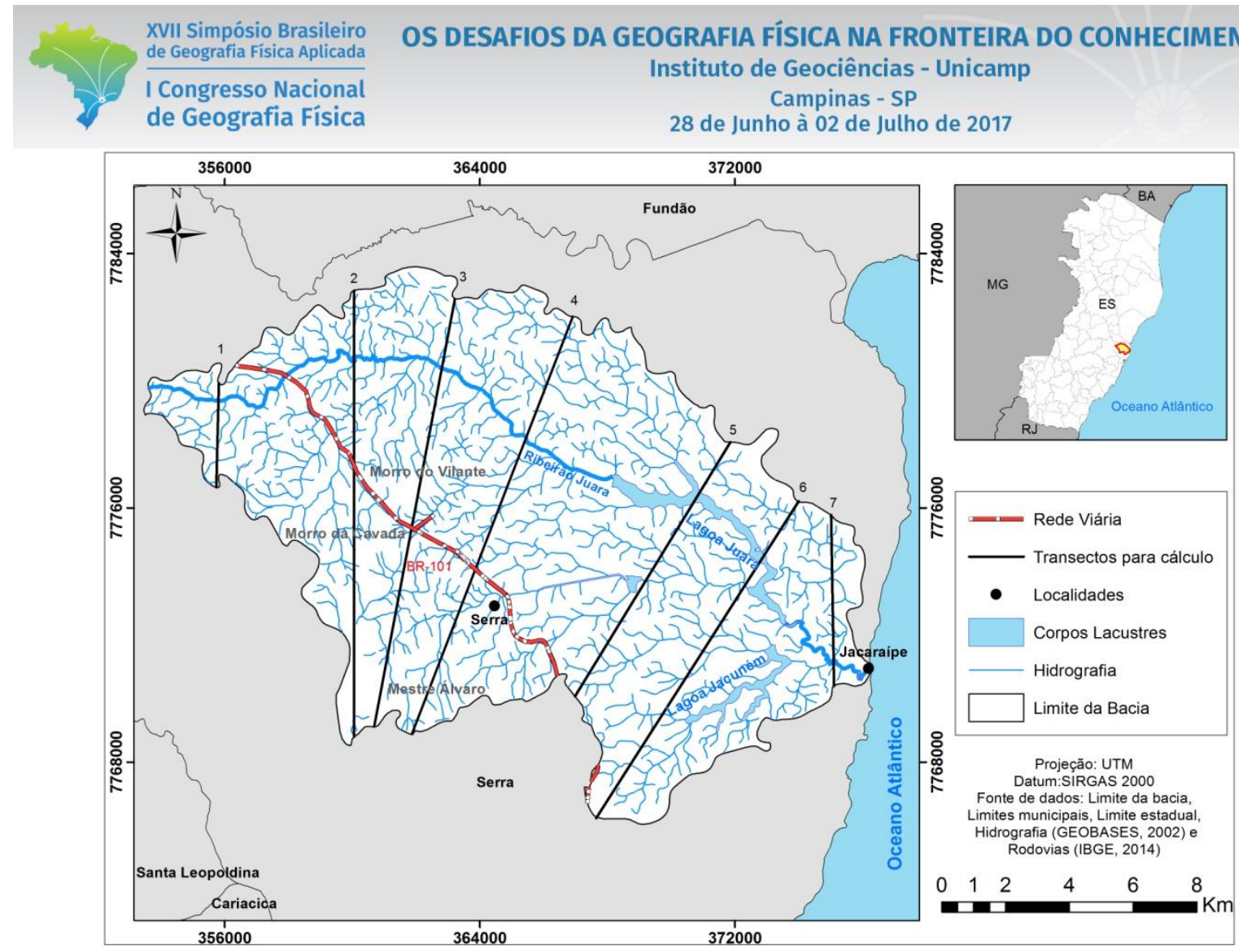

Figura 2 - Mapa de localização dos transectos de cálculo de assimetria da bacia do rio Juara (Espírito Santo).

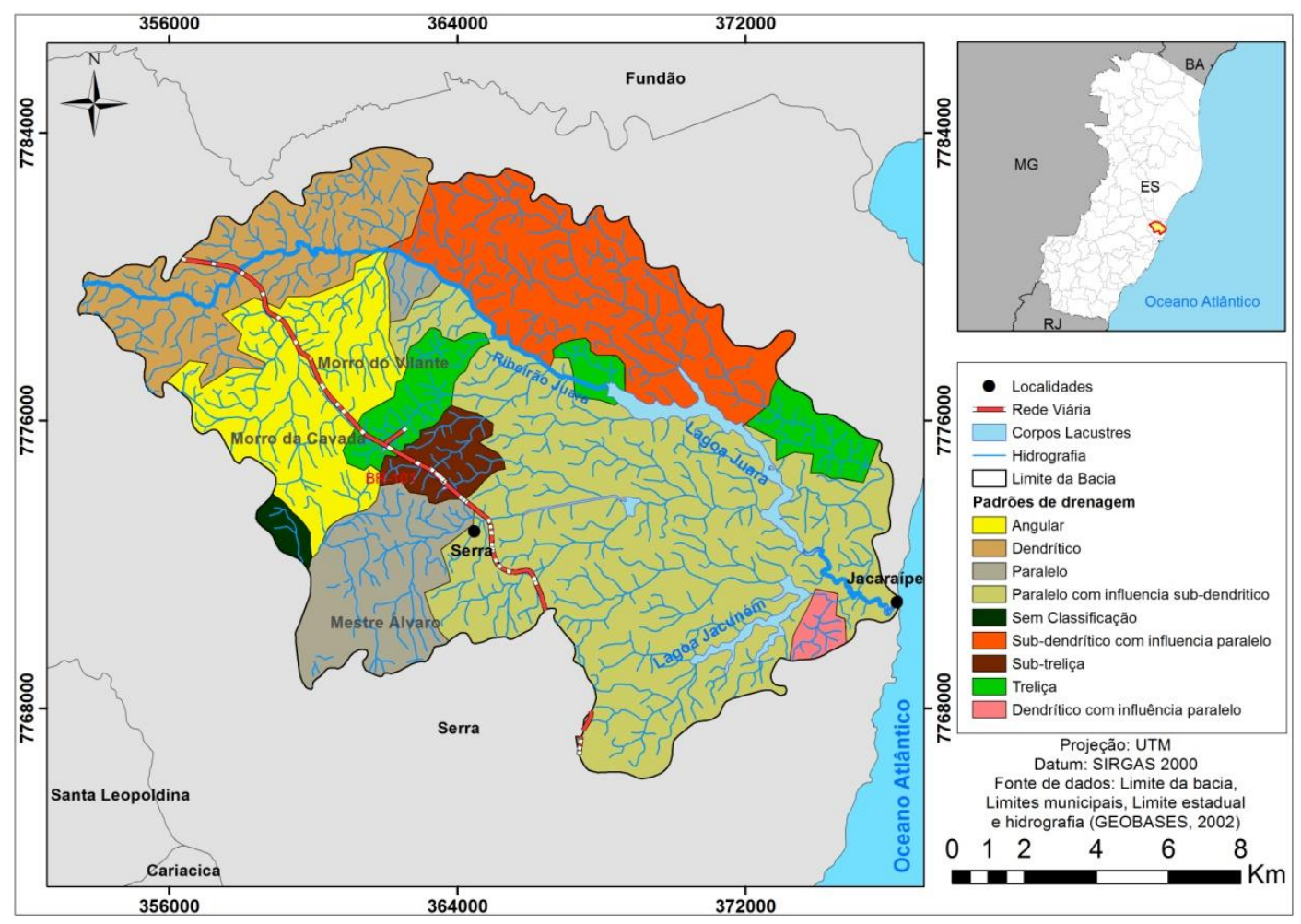

Figura 3 - Mapa de padrões de drenagem da Bacia do rio Juara (Espírito Santo), apresentando padrões de drenagem com forte controle tectônico e morfoestrutural 
O padrão de drenagem que predomina na bacia é o padrão "Paralelo com influência do subdendrítico", predominantemente sobre as rochas sedimentares da Formação Barreiras, a leste da área de estudo (Figura 3). Esse padrão é caracterizado pelo paralelismo de suas drenagens (LIMA, 2002), com forte controle tectônico, refletindo o fraturamento neotectônico dessas rochas (BRICALLI, 2011). Os outros padrões encontrados (Paralelo, "Sub-dendrítico com influência de Paralelo", "Dendrítico com influência de Paralelo", Treliça, Sub-treliça e Angular) apresentam forte controle tectônico (HOWARD, 1967; LIMA, 2002; BEZERRA, 2003), com exceção dos padrões dendríticos e sub-dendríticos que não apresentam controle tectônico e sim litológico. Além disso, nessa bacia existem duas lagoas retilíneas e alinhadas (Lagoa Juara e Lagoa Jacunem), de grande porte, compatíveis com condicionamento neotectônico.

\section{Considerações Finais}

Com a análise dos resultados é possível dizer que provavelmente a bacia do Juara sofreu processos tectônicos, devido ser constatado que a bacia é assimétrica, e também por conter por toda sua extensão padrões de drenagem controlados por falhamentos e Juntas, além da presença de Lagoas encaixadas. Através da análise dos mapas elaborados é possível identificar que a bacia pode ter forte controle tectônico, predominantemente à leste da Bacia, nas rochas sedimentares, principalmente nos depósitos da Formação Barreiras, que como atesta Bricalli (2011), que descreve a ocorrência de eventos Neotectônicos no Espírito Santo, os eventos nesse Estado tem em sua maioria a orientação NE-SW, ENE-WSW e WNW-WSE, que podem ser os possíveis atuantes na moldagem da configuração atual da drenagem e consequentemente do relevo da Bacia,.

O próximo passo da pesquisa será a elaboração de um mapa de anomalias de drenagem e realização de idas à campo, para a procura de falhas em afloramentos e feições morfotectônicas por diversos pontos da Bacia, para uma melhor análise e confirmação sobre o constatado em gabinete.

\section{Referências Bibliográficas}

BEZERRA, P. E. L. Análise estrutural da drenagem. IBGE: Belém, 2003.

BISHOP, P. Drainage rearrangement by river capture, beheading and diversion. Progress in PhysicalGeography, 19(4):449-473, 1995.

BRICALLI, L. L. Padrões de Lineamentos e Fraturamento Neotectônico no estado do Espírito Santo 
(sudeste do Brasil). Rio de Janeiro: Instituto de Geociências (UFRJ), 2011 (TESE DE DOUTORADO).

BRICALLI, L.; MELLO, C. Padrões de lineamento relacionados à litoestrutura e ao faturamento neotectônico (estado do Espírito Santo, SE do Brasil). Revista Brasileira de Geomorfologia, São Paulo, v. 14, n. 03, p. 301-311, 2013.

BUSATO, C. Landforms tectônicos e controle neotectônico na rede de drenagem da bacia do rio Piraquê-Açu (Espírito Santo-Sudeste do Brasil). Trabalho de Conclusão de Curso. (Graduação em Geografia) - Universidade Federal do Espírito Santo, 2014.

COX, R.T. 1994. Analysis of drainage-basin symmetry as a rapid techique to identify áreas of possibleQuaternay tilt block tectonics: as example from the Mississipi Emayment. Geological Society of América Bullelin, 106: 571-581.

HOLBROOK, J \& SCHUMM, S.A. 1999. Geomorphic and sedimentary response of rivers to tectonic deformation: a brief review and critique of a tool for recognizing subtle epeirogenic deformation in modern and ancient settings. Tectonophysics, 305: 287-306.

HOWARD, A .D. 1967. Drainage analysis in geologic interpretation: a summation. American Association of Petroleum Geologie Bulletim, 51(11): 2246-2259.

LIMA, M. I. C. Análise de drenagem e seu significado geológico-geomorfológico. Belém, 2002. CD-ROM.

SCHUMM, S.A . 1986. Alluvial river response to active tectonics. Wallace R.E ed, Active Tectonics,National Academy Press, 80-94.

SOUZA, B.S. Caracterização Geológica e Geomorfológica da bacia do Juara (Espírito Santo-Sudeste do Brasil). 2015. Trabalho de Conclusão de Curso. (Graduação em Geografia) - Universidade Federal do Espírito Santo.

SUMMERFIELD, M.A . 1987. Neotectonics and landform gênesis. Progress in Physical Geology, 11: 384-397.

\section{Agradecimentos:}

À Fundação de Amparo à Pesquisa e Inovação do Espírito Santo (FAPES) pela bolsa concedida para realização da pesquisa de PIBIC na Universidade Federal do Espírito Santo (UFES) e ao Grupo de pesquisa Neotectônica no Espírito Santo, pelas valiosas discussões. 